\title{
El periodismo de Muñoz Molina: su tiempo de silencio
}

\author{
Miguel Sánchez \\ Asociación Universitaria Comunicación y Cultura, investigador y periodista
}

\begin{abstract}
Antonio Muñoz Molina combina el periodismo literario con su trabajo como novelista. El articulista considera que su literatura y su periodismo salen mutuamente enriquecidos. Para Muñoz Molina el periodismo es un género soberano, no incompatible con la literatura. La verdadera fuerza de la escritura se halla en la capacidad de las palabras para sugerir y denunciar. El poder de escritores y periodistas es contribuir a airear las injusticias. También tienen el compromiso con el arte y la estética; lo que escriban ha de sonar bien y producir placer.
\end{abstract}

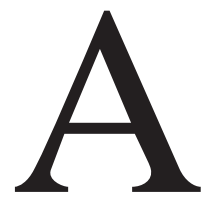

seguraba Pavese ${ }^{1}$ que la literatura es una defensa contra las ofensas de la vida. La otra defensa contra las cosas, decía, es el silencio acumulado para el arrebato. Los silencios que entre novela y novela se impone Muñoz Molina encerrado en su Nautilus $^{2}$, "que no es buque de guerra, sino refugio submarino contra las crudas afrentas de la realidad", los aprovecha para vivir y para mantener un diálogo con el presente a través del periodismo. En ese interminable tiempo de silencio para sus incondicionales, lejos de prepararse para el arrebato, o la vehemencia y la ira como aseguran algunos, aprovecha, como mucho, para indignarse y "para hacer una defensa melancólica pero muy obstinada de algunas cosas que le importan mucho: la instrucción pública, la racionalidad, la justicia, la buena educación"3 . Y además es capaz de conseguir todo eso haciendo al mismo tiempo buena literatura; o mejor, como diría el vanidoso de González Ruano ${ }^{4}$, una literatura en sí que se publica dentro de los periódicos.

\footnotetext{
PAVESE, Cesare. El oficio de vivir. Bruguera. Barcelona, 1990, p. 185

MUÑOZ MOLINA, Antonio. Diario del Nautilus. Mondadori. Madrid, 1989, p. 19

MUÑOZ MOLINA, Antonio. La huerta del Edén. Ollero y Ramos editores. Madrid, 1996, p. 10.

GONZÁlEZ RUANO, César. Diario íntimo. Taurus. Madrid, 1970, p. 69
} 
La literatura fuera de los libros ha servido desde siempre para menesteres innobles e impropios de la utilidad inicial para la que fue pensada. El mejor Julio Camba terminaba cada día colgado de un alambre en los excusados, mientras que hoy, que se ha abaratado el coste del papel higiénico, Umbral o Muñoz Molina no perecen en el retrete sino reciclados, salvando el bosque, o quemándolo en una antorcha en las manos del algún pirómano trasnochado. En cambio, ya lejana la Inquisición, el seguro y reposado destino de los libros parece que es dormir el sueño de los justos en una estantería comprada por metros cuadrados. La trampa para quienes quisieran poseer ideas, madurez y tiempo suficientes para escribir novelas, es entender la literatura periodística y efímera como un escalón imprescindible para acceder al rellano de la literatura inmortal. Después, salvo contadas excepciones, esto resulta mentira. El propio Ruano afirmaba que de poco servía el triunfo para quien, como él, había soñado con la gloria. El sevillano Manuel Ferrand advertía a quien fuese para escritor que tenía que dejar a tiempo de ser periodista. Entre las contadas excepciones en las que lo anterior resulta falso está la excepción de Antonio Muñoz Molina, quien empezó haciendo periodismo literario y luego saltó a la novela, de la que vuelve y a la que regresa desde el articulismo cada vez que le apetece y sin que ninguno de los dos géneros (ni él) se resientan. Antes bien, su literatura y su periodismo salen mutuamente enriquecidos.

Cuando el autor de Los misterios de Madrid confiesa que los artículos tienen que ser el fruto de un arrebato ${ }^{5}$, lo dice más en el sentido de la intuición o la espontaneidad que en el de la explosión largamente larvada y pavesiana que de manera indefectible desemboca en el suicio o el asesinato. En todo caso, cuando conduce a lo segundo y llega a los periódicos como quien en su Beltenebros acude a Madrid para matar a alguien, los jueces lectores siempre le aplicarán la eximente penal y literaria del arrebato que tiene lugar en nombre del compromiso con las causas perdidas de las cajeras del Pryca o los mendigos granadinos y sempiternos que, a las puertas del siglo XXI, repiten el atraso andaluz y el Barroco.

Está convencido de que muchos escritores desdeñan hacer literatura en los periódicos, o lo hacen sólo de una manera mercenaria, para ganar dinero.

\footnotetext{
"La clave del artículo, lo que le da su carácter específico, aparte del tamaño o su carácter periódico, es la espontaneidad. No puede ser una cosa elaborada, debe ser fruto de un arrebato. Un artículo se hace con una intuición o, lo máximo, con dos intuiciones que, al chocar, hacen saltar una chispa". ABC Literario. Entrevista con Juan Manuel de Prada, de 1997, p. 18 .
} 
Sin embargo para él el periodismo es un género soberano. "Una de las grandes cosas que pueden hacerse en la vida es escribir en periódicos: artículos, crónicas, reportajes, entrevistas... lo que sea"

Muñoz Molina es maestro de la ironía, esa salida agridulce de la inteligencia que sabe que escribir, como llorar para Solón, no sirve para gran cosa o para nada aparte de dejar testimonio. Con ironía o sin ella tiene claro ${ }^{7}$ que la fuerza de las palabras, el poder impactante que se asigna a la letra impresa, a la escritura, no sólo estriba en el milagro de comunicarnos a través de ella mediante unos códigos aceptados, aun cuando el emisor haya muerto hace veinte siglos o se encuentre en otro continente. La verdadera fuerza de la escritura se halla en la capacidad de las palabras para sugerir y denunciar; el poder de escritores y periodistas no es otro que contribuir desde la tribuna de un periódico o las páginas de un libro a airear las injusticias, domésticas o mundiales, que conforman (y deforman) la historia con el propósito de cambiar su rumbo. Dedicarse a hacer poesía tras Auschwitz, casi sesenta años después del holocausto, aún sigue siendo una barbarie. Antonio Machado desdeñó en sus versos "la romanza de los tenores huecos que cantan a la luna", ésos que sólo escriben de los colores del pavo real (o del azahar y desde la grasia andaluza) mientras los niños descalzos rebuscan entre la basura. $\mathrm{Su}$ tocayo Muñoz Molina tampoco pierde el tiempo haciendo chistes o contando/cantando los colores del arco iris. El escritor, el periodista y el poeta tienen un ineludible compromiso con el arte y con la estética; lo que escriban ha de sonar bien y producir placer; mas por encima de la eufonía de la literatura o de la prosa periodística, sobre los demás artistas, ninguno de los tres puede perder de vista el compromiso con la sociedad de su tiempo, la rebeldía ante los estados injustos de cosas y ante tantas otras situaciones sangrantes que en el mundo se prodigan. Fiel a su destino, Muñoz Molina hace periodismo porque no se conforma y porque "se niega a aceptar que la huerta del Edén exista sólo en el pasado y en la literatura".

De los cuatro libros en que se recogen sendas selecciones de artículo del autor de El invierno en Lisboa, sin duda ninguna La huerta del Edén es el más periodístico, si por periodismo entendemos aquella narración impresa que se hace al hilo de la actualidad. El Robinson urbano (1984), Diario del Nautilus (1985) y Las apariencias (1995) son en cambio novelas completas,

\footnotetext{
Ib. citado, p. 18

"Nadie debería guardar sus pensamientos, y yo no callaré ni aun debajo del agua". Declaraciones del autor el 4-8-94 en Diario 16-edición Andalucía, p. 40.
} 
cerradas y perfectas de dos páginas en las que a veces encontramos el embrión de un libro posterior que se lleva al cine y por el que, beatus ille, le dan a pares los premios Nacionales de Literatura o los de la Crítica.

Dice el autor que la huerta del Edén es la Andalucía que se convirtió en un recuerdo de fertilidad y belleza sin haber llegado nunca plenamente a existir; pero también es la huerta de su padre y la de su abuelo Antonio y es la huerta que fue un paraíso literal para sus ojos infantiles. De recuerdos, sentimientos y compromisos este jinete audaz de la literatura y el periodismo, más de sierra Mágina que polaco, hizo un libro de artículos desde y sobre Andalucía. Veamos qué da la huerta de Muñoz Molina.

\section{La instrucción pública y su maestros}

"La Educación es una prioridad en la sociedad contemporánea. La democracia tiene como problema público la Educación. Y son dos cosas diferentes. No es solamente la enseñanza pública, lo que es público es el problema de la Educación ${ }^{8}$ ". El número de artículos que de manera específica o indirecta Muñoz Molina dedica a la educación, confirma su declaración de intenciones, esas defensa suya obstinada y melancólica de las cosas que tanto le importan. Junto con Savater ${ }^{9}$ entiende que entre los baremos básicos que pueden señalarse para calibrar el desarrollo humanista de una sociedad, el primero es el trato y la consideración que brinda a sus maestros. Existe el hábito de señalar a la escuela como correctora de todos los vicios de la sociedad, males entre los que destacan la violencia juvenil, la drogadicción, el retorno al racismo... En lógica consecuencia se supone que los encargados de esa primera enseñanza de tan enorme trascendencia han de ser profesionales a cuya preparación se dedica el mayor celo profesional, los mejores dotados de medios, los más remunerados y los que gozan de la máxima audiencia en los medios de comunicación. Porque los maestros son en suma quienes preparan para que los niños aprendan a disfrutar la conquista cultural por excelencia: el sistema mismo de convivencia democrática. Para Savater, educar es creer en la perfectibilidad humana, en la capacidad innata de aprender y en el deseo de saber que las anima, así como en la creencia de que los hombres podemos mejorarnos unos a otros por medio del cono-

\footnotetext{
8 SAVATER, Fernando. "La educación es una prioridad de la sociedad contemporánea". Entrevista en Andalucía Educativa. Consejería de Educación y Ciencia de la Junta de Andalucía, nº 6, diciembre 1997.

9 SAVATER, Fernando. El valor de educar. Ariel, Barcelona, 1997, pp. 7-8
} 
cimiento. Sin embargo la realidad que Savater y Muñoz Molina observan en torno al magisterio y al mundo de la enseñanza, en general, nada tiene que ver con tales exigencias:

"Apenas inaugurados, los centros públicos de enseñanza adquieren un aire desalentador de abandono, en correspondencia con el estado anímico de los maestros y de los profesores, que asisten cada día a la degradación y al menosprecio oficial de un trabajo, el suyo, que debería poseer una dignidad suprema en la democracia, y que está mal pagado, mal considerado, sometido a la sospecha, abandonado al antojo de las asociaciones de padres más arbitrarios e ignorantes, un oficio tan dejado de la mano de Dios como las aulas y los corredores que lo albergan"10 .

Con Savater coincide asimismo en que el sentido de la educación es conservar y transmitir el amor intelectual a lo humano, y en que en más ocasiones de lo tolerable se equivoca el enfoque de dicho contenido:

"La señora consejera de educación, que ha anunciado el reparto por los colegios de la comunidad de no sé cuántos millones de folletos sobre el enigmático Legado Andalusí, ha declarado que esta iniciativa de su consejería viene a incrementar los ya ricos programas de cultura andaluza que se imparten en las escuelas, cuya finalidad, asegura ella, es lograr un mayor conocimiento "de todo lo que es el ser andaluz". Yo incluso lo escribiría con mayúsculas, para mayor impacto: el Ser Andaluz. A nuestros hijos, en las escuelas andaluzas, apenas les enseñan a leer y escribir, y cualquiera que se moleste en hojear los libros descubrirá que lo que antes era la Geografía, la Historia, las Ciencias Naturales, se ha convertido en una halagüeña papilla mental gracias a la cual los niños llegarán a la adolescencia con una disciplina intelectual digna de una guardería, y con una idea del mundo aproximadamente tan ajustada y tan compleja como la de El rey león."11

En esta guerra en que ha devenido la enseñanza en ningún caso el autor de Córdoba de los omeyas deja lugar a dudas junto a quién se sitúa:

"Leo hace unos días, en este periódico, una noticia marginal que de vez en cuando se repite, más o menos idéntica: un maestro ha sido acusado de malos tratos a los alumnos por un grupo de padres. El nombre del maestro y sus dos apellidos se publican, por supuesto, y en este caso al que me refiero ahora viene una información complementaria especialmente vil: se dice que

\footnotetext{
${ }^{10}$ MUÑOZ MOLINA, Antonio. La huerta del Edén. "Una celebración”, p. 32. Ollero y Ramos Editores. Madrid, 1996

${ }^{11}$ Idem, "Los misterios del ser", pp. 139-140.
} 
este maestro ha tenido problemas de alcoholismo en algún momento de su vida. Cuando la policía detiene a un presunto atracador o asesino los periódicos publican nada más que las iniciales de los nombres, en primer lugar porque en un sistema jurídico civilizado nadie es culpable mientras no se pruebe su delito, y también por un principio de clemencia y de respeto a la intimidad de las personas al que tiene derecho todo el mundo, incluido los criminales. Todo el mundo, parece, salvo un maestro o un profesor de instituto a quien algún padre de alumno acuse de haber maltratado a su hijo. (...) Los demagogos oficiales de la educación quieren hacernos creer que despojar al maestro de respeto y de dignidad frente a los alumnos y someterlos a las arbitrariedades y a las inquisiciones de los grupos de padres son adelantos democráticos, incluso actitudes de izquierda. (...) Ya que les han quitado casi todos los medios para ejercer dignamente su oficio, podían dejarles al menos la presunción de inocencia"12 .

Frente a la significada inquisición de los progenitores contra los maestros, el autor cita otras formas más civiles y civilizadas en las que un padre puede estar junto a sus hijos:

"Yo me veía, acompañando a mis hijos en la biblioteca, como un padre republicano y antiguo que trata de inculcarles el respeto y el afecto por los valores laicos, por la lectura y los buenos modales y la reverencia hacia los lugares públicos, que son los lugares donde uno ejerce con plenitud su humanidad civil"13.

“(...) Eso me trae el recuerdo de esos padres, tan habituales ahora, que siempre encuentran disculpa para cualquier tontería o barbaridad que hagan sus hijos, y que acuden escandalizados a la escuela y amenazan a los profesores y hasta los denuncian si consideran que su niño ha padecido el más leve contratiempo"14.

"La maestra a la que el otro día le dio una paliza la madre de un alumno en un colegio público de san Roque no está de baja por accidente, sino por depresión. Duele que le peguen a uno y duele más la humillación del abuso, pero sobre todo debe doler dedicarse a un oficio mal pagado y mal mirado en el que empezó por perderse el derecho al respeto y ya se está perdiendo la seguridad personal. (...) En Francia, los profesores de escuela primaria y de bachillerato cobran un suplemento para gastos de terapia psicológica. (...)

\footnotetext{
12 Idem, "Maestros bajo sospecha", pp. 153-156.

13 Idem, "Elogio laico de la biblioteca", pp. 40-41.

14 Idem, "El heroísmo de los encapuchados", P. 186.
} 
Ahora se comprueba que la escuela se está volviendo un sitio peligroso, no sólo para los maestros, sino también para la mayoría de los niños, para los que no son brutos ni consentidos ni chulos y no cuentan con la arrogancia impune de la fuerza física y la indulgencia de un padre o una madre a los que la educación de su hijo trae sin cuidado. (...) Lo raro no es que algunos maestros vivan en un estado de desánimo y depresión permanente. Lo más raro es que tanto de ellos sigan teniendo la integridad y el coraje de cumplir cada día su trabajo en la escuela"15.

\section{Denuncia, compromiso e ideología en Muñoz Molina: Ahí hay un hom- bre que dice ;ay!}

En uno de los artículos antes citado en defensa de lo maestros, Muñoz Molina confiesa que fue a la escuela en la época infame de la palmeta y de las bofetadas, en los aborrecibles tiempos en los que era preceptivo escribir al dictado. A este último respecto, el método infalible que tenía el maestro para comprobar si la anarquía de los mocosos había sucumbido a la rígida convención de la ortografía, era mandar a los colegiales que guardasen bien lejos sus diccionarios Iter de bolsillo y, una vez provistos de papel virgen y lápiz mordisqueado, dictarle al niño Muñoz Molina que "junto a la pared había una bonita lámpara, que en la oquedad había varios huecos y que ahí hay un hombre que dice ¡ay!" Para los compañeros de Antonio de pocas entendederas y menos espíritu crítico, resultaba muy cómodo que otros pensasen por ellos. Se limitaban a llenar la página incoherente alternando las bes y las uves al cincuenta por ciento y guardaban sus mejores fuerzas para el recreo. La mayoría de aquellos niños hoy, treinta años después, continúa escribiendo y viviendo al dictado y dejan que el mundo siga su curso mientras disfrutan de un ramplón concurso televisivo o de las interminables horas muertas de bebedores sociales acodados en el bar de la esquina. Por el contrario, Muñoz Molina demuestra que sigue sin escribir al dictado, haciéndolo con su propia conciencia y su propia voz, y encima respetando la ortografía y la sintaxis. El cordial o intratable enemigo que todos tenemos lo ha acusado en alguna ocasión de que, al igual que todos los que escriben, el señorito Molina, uno de los cien famosos escritores de doña Carmen Romero, andaba buscando una subvención, una nómina, un algo. Y los cordiales o intratables enemigos llevan razón en parte. Y aciertan en lo del

\footnotetext{
15 Idem, "Un oficio peligroso", pp. 193-196.
} 
acto de la búsqueda, mientras que su maldad les hace errar en el objeto de lo que busca. De alguna forma hay que comprender a estos eruditos a la conciencia, porque es sabido que tales personajes, siempre a cuestas con la pesada y paseada cruz de los envidiosos, hacen tabla rasa y meten a la humanidad en el mismo saco en la innoble creencia de ladrón de que todos son de su misma condición.

Muñoz Molina está convencido de que vivir en sociedad implica algo más que habitar en determinado territorio para hacer bulto. Ser socio es cooperar a un fin común, aportar ideas y esfuerzos para que la sociedad progrese, y lo haga en un progreso más entendido en el ámbito humanista que en el meramente tecnológico. Los torpes de condición y de corazón jamás entenderán esto; por ello, en las raras excepciones que leen un artículo, su maldad y el no concebir la vida sino como un cortijo de intereses personales les lleva a errar el mensaje y a leer lo que no está ni pensado ni escrito por ningún sitio. Ante la denuncia por alguna incoherencia de determinadas siglas políticas, el torpe enemigo afiliará a Muñoz Molina al partido de signo contrario y le acusará de ser un plumífero o plumilla a sus órdenes. Sin embargo la realidad, contra las apariencias que creen descubrir tales miopes morales, es otra cosa y la independencia (si por independencia se interpreta la libertad y la obligación de arremeter contra el que la hace) está garantizada en sus columnas. Al fin y al cabo el oficio de los poetas es tronar:

“(...) Lo único que me temo es que entre los visitantes haya algún alto cargo de la Consejería de Educación de la Junta de Andalucía, y que en el próximo curso nuestros hijos, que ya estudian cultura andaluza e historias de marcianos, tengan una asignatura de elaboración de cartas astrales"16.

“(...) Había que emular a Sevilla: había que levantar edificios que compitieran con los de la Expo, con los hoteles y palacios y teatros de la ópera que ahora ni siquiera tienen dignidad de ruinas verdaderas, sino un aspecto de ruinas falsas de decorado de película, reliquias de una magalomanía edificatoria (...) El Palacio de Congresos de Granada, como los edificios fantasmales de la Isla de la Cartuja, los teatros con escenarios inmensos en los que no se representa nada y los hoteles de lujo convertidos en una aritmética de habitaciones vacías, es un testimonio inmediato y sin embargo ya arqueológico de un tiempo de delirio, de una era de los faraones que apenas

${ }^{16}$ Idem, "Tiempos oscuros", pp. 85-86. 
duró diez años y que ha ingresado ya en la estética triste y aleccionadora de las ruinas de soberbias pasadas"17.

"Que los directivos de una televisión costeada con el dinero público se indignen porque aparezca en ella un curandero es una noticia alentadora, aunque también alarmante: indica que sus principios ideológicos y morales son muy sólidos, pero sobre todo indica que no ven la televisión que ellos mismos dirigen, porque si la vieran sabrían que lleva años convirtiéndose en un zoco de charlatanes, santeros, astrólogos y traficantes del comercio más bajo que existe, que es el comercio de la ignorancia, del miedo y del dolor"18.

Parece que ni con "los suyos" deja de despacharse a gusto y ni siquiera se priva del saludable ejercicio de la ridiculización y la ironía:

"La Junta de Andalucía ha tomado una decisión que viene a remediar una necesidad urgente de nuestra tierra: fundar o patrocinar una escudería de coches de carreras. Cuando lo leí sentí un alivio y una gratitud semejantes a los que ha producido en los ciudadanos de Madrid la adquisición por el gobierno regional de un caballo de pura sangre (...) Claro que en esto del marisco, como en las carreras de coches, quienes llevamos las de ganar somos también los andaluces, que pagamos hace años, con la generosidad que nos caracteriza, un célebre crucero en bateau mouche por el Sena, en el cual nuestras autoridades superaron un récor, no superado aún, en el consumo de langostinos de Sanlúcar"19.

Después de los fragmentos anteriores sería un sarcasmo acusar a Muñoz Molina de pesebrero socialista. Ahora bien, con la derecha tampoco se muerde la lengua:

"También ahora tengo más claro quiénes son los otros. La recién nombrada ministra de Educación y cultura, Esperanza Aguirre, a quien ya se le conocían sus méritos temibles como concejala en el ayuntamiento de Madrid, ha declarado con toda claridad, con perfecto impudor, que una de sus tareas inmediatas va a ser la de cerrar escuelas públicas 'no rentables' (sic) e incrementar las subvenciones a las escuelas privadas más favorecidas por los padres (...) Dice Kenneth Galbraith que lo que está ocurriendo en el mundo es una revolución de los ricos contra los pobres. A los pobres van a escatimarles ahora las escuelas públicas para que los ricos asistan con mayor comodidad y menos gasto a sus escuelas privadas, y a uno vuelve a subírsele

\footnotetext{
${ }^{17}$ Idem, "La edad de los faraones", pp. 87-90.

${ }^{18}$ Idem, "Tecnología del oscurantismo", p. 91.

${ }^{19}$ Idem, "Escudería de Cultura", pp. 96-97.
} 
la sangre jacobina y se le definen otra vez los puntos cardinales de su diatriba política (...) De nuevo hay que defender la escuela pública. De nuevo hay que cuidar con celo vigilante la libertad de expresión, porque a la derecha, en cuanto gana, le vuelve el viejo instinto de prohibir"20 .

En "Melancolía liberal" (pp. 143-146), entre otros artículos, deja claro con quién está, cuál es su ideología, quiénes son los suyos:

"Después de más de una década a las personas de izquierdas nos está cambiando ahora el signo de la melancolía, que según dejó escrito Mariano José de Larra es el signo más arraigado de los liberales españoles (...) Todos estos años atrás, muchos demócratas y liberales españoles -usando la palabra liberal en su sentido noble y antiguo, no como ese sinónimo de canibalismo económico en que se ha convertido últimamente-, nos hemos sentido solos, dispersos en minorías robinsonianas de misantropía o naufragio (...) Al cabo de mucho tiempo yo dejé de sentirme en una minoría de uno cuando asistí a la memorable manifestación contra el terrorismo que se celebró en Madrid después del asesinato de Francisco Tomás y Valiente: aquella multitud lenta y torrencial que subía por la calle de Alcalá hacia la Puerta del Sol en una noche helada eran, sin la menor duda, los míos".

"De una manera íntima, casi siempre en privado, los republicanos españoles seguimos celebrando nuestra fiesta nacional (...) y erigimos esa bandera tricolor que tiene toda la poesía de lo perdido y de lo inútil, toda la belleza de la afirmación de un patriotismo no basado en la xenofobia, ni en la irracionalidad, ni en la más burda antropología inventada, sino en los pocos principios que desde el siglo XVIII han vuelto menos inhabitable el mundo: la libertad, la igualdad y la fraternidad, la primacía de la razón frente a la fuerza, la instrucción pública, el laicismo"21.

\section{Pandereta y rogativas}

Ortega advertía que el ruralismo era el signo más característico de una sociedad sin minoría eminente: "Cuando se atraviesan los Pirineos y se ingresa en España se tiene siempre la impresión de que se llega a un pueblo de labriegos ${ }^{22}$.

${ }^{20}$ Idem, "Melancolía liberal", pp. 144-145.

${ }^{21}$ Idem, "Catorce de abril", p. 158.

${ }^{22}$ Hay pueblos que se quedan para siempre en ese estadio elemental de la evolución que es la aldea. Podrá ésta contener un enorme vecindario, pero su espíritu será siempre labriego. Pasarán por ella los siglos sin perturbarla ni estremecerla. Entre siembra y recolección o análogas tareas vivirá eternamente, prisionera en el ciclo siempre idéntico de su destino vegetativo (...) Generaciones después vuelve a caer en una inercia histórica de la que no ha salido todavía, y en sus venas la sangre circula con lento pulso campesino”. Ortega y Gasset, José. España Invertebrada. Espasa Calpe, Madrid, 1977, 
Muñoz Molina repara en todos esos provincianismos dañinos, en los chovinismos y en el tiempo ya para siempre perdido mirándonos el ombligo y tocando la pandereta, acudiendo antes a las rogativas que a las ciencias, cómodamente instalados en nuestro atraso finisecular y andaluz.

“(...)No creo que muchas personas progresistas hubieran podido vaticinar lo que ocurrió después: que con la democracia y los gobiernos de izquierdas no llegó para Andalucía la liberación de la ignorancia, ni del atraso, ni de la superstición, ni del folklorismo. Lo que vino, lo que ya nos inunda, es exactamente lo contrario, la fiebre irracional e intimidatoria por todas las fiestas y tradiciones posibles, la vanagloria inepta en los localismos más agresivos y cerrados, la feria eterna, la romería y la procesión eternas, programadas por la autoridad, alentadas por la radio y la televisión públicas, convertidas en una especie de narcótico brutal"23.

"Ya que a las personas no se les podían ofrecer días de trabajo, al menos se les regalaban días de fiesta. Se fundaron academias de sevillanas, se procedió a un apostolado masivo sobre el Rocío, se dedicaron horas dolorosas y tenaces de estudio al logro del acento adecuado y de las entonaciones correctas para contar chistes" 24 .

"En eso sí que se nota que Ian Gibson es extranjero, porque no hay español que tenga la paciencia y la humildad necesarias para dedicar su vida a investigar la vida de otro (que casi no haya biografías en España no es un problema de ignorancia, sino de soberbia)" 25

$\mathrm{Si}$ en el artículo se airea las profundas contradicciones de sectores de la iglesia, los tartufos de nuestro tiempo verán en el firmante al más depravado ateo:

"La Iglesia católica, al fin y al cabo, garantiza la existencia del demonio y de las curaciones milagrosas, y durante siglos tuvo una cierta propensión a la quema de brujas. También se caracteriza dicha iglesia, al menos en algunas de sus diócesis, por una acendrada defensa de las culturas aborígenes. Desde los tiempos de la primera guerra carlista hasta la actuales hazañas de ETA y Jarrai, en el País Vasco no ha sido infrecuente el vínculo entre las sotanas y las armas. Y en Cataluña, no hace mucho, los obispos tuvieron el gesto ecuánime de lamentar que en sus territorios pastorales se continuaran diciendo misas en castellano"26.

\footnotetext{
${ }^{23}$ Muñoz Molina, Antonio. Opus. citado a “Andalucía obligatoria”, pp. 149-150.

${ }^{24}$ Idem, "Los objetores de la fiesta", pp. 36-38

${ }^{25}$ Idem, "Un extranjero en su país:, p. 61

${ }^{26}$ Idem, Tiempos oscuros", pp. 83-84.
} 
“(...) Que el Ayuntamiento de Granada publique un bando de proselitismo religioso, aunque no estuviera redactado con faltas de ortografía y en una prosa del peor paleolítico franquista, no es tanto una barbaridad como una ilegalidad. No puedo sino aplaudir las tardías palabras de Jesús Quero, pero no me olvido de que hace unos meses su compañero de partido José Rodríguez de la Borbolla declaró que uno de los motivos por los que quería ser alcalde de Sevilla era para presidir la procesión del Corpus. A cinco años del siglo XXI parece que no hay modo de salir del siglo XIX."27

Existen innumerables pruebas, incontables ejemplos vivientes de que al homo sapiens de nuestros días se le compra, se le calla o se le programa por el misérrimo precio de un coche repostado con gasolina oficial. El engolfamiento y envilecimiento de que un chófer vestido de chófer te abra la puerta del coche hoy, por lo común, puede más que todos los portazos de la verdad. Muñoz Molina viaja en metro en Madrid y en Úbeda sigue paseando a pie por las mismas calles en las que hace más de treinta años paseaba del brazo de su madre. Al más inconformista con tribuna sólo hay que darle un tratamiento honorífico para volverlo como un calcetín y lograr que se meta sus principios y sus ideales por semejante sitio. El hombre de carne y hueso por el que empieza Unamuno es el que nace y sufre y muere y siente todo eso en lo más profundo de su ser. El rector de Salamanca, a cuestas con su sentimiento trágico de la vida, afirmaba que la conciencia era una enfermedad. No parecerse demasiado a una rana o a una lagartija tiene algunos inconvenientes de última hora que no todos saben arrostrar. En ese sentido Antonio Muñoz Molina, con su enfermedad, es decir con su conciencia, los afronta para dignificar al periodismo y al hombre. Habría que agradecérselo.

${ }^{27}$ Idem, "Gestos tardíos", pp. 81-82. 